UCRL-CR-137131

B503785

\title{
Intermittent Single Point Machining of Brittle Materials
}

E. Marsh

December 7, 1999

U.S. Department of Energy

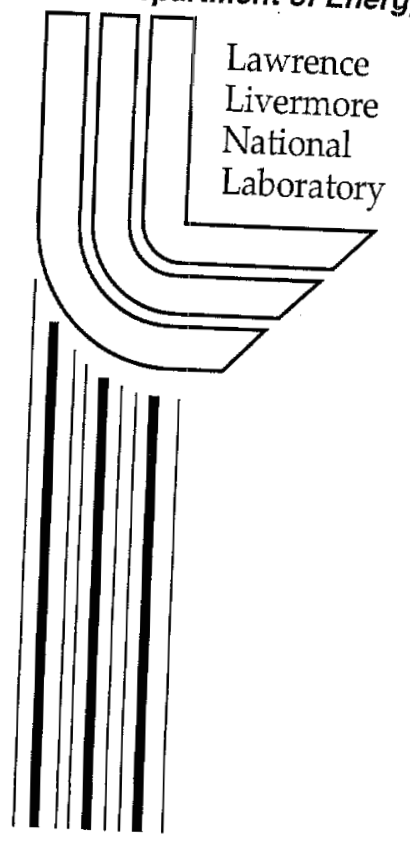




\section{DISCLAIMER}

This document was prepared as an account of work sponsored by an agency of the United States Government. Neither the United States Government nor the University of California nor any of their employees, makes any warranty, express or implied, or assumes any legal liability or responsibility for the accuracy, completeness, or usefulness of any information, apparatus, product, or process disclosed, or represents that its use would not infringe privately owned rights. Reference herein to any specific commercial product, process, or service by trade name, trademark, manufacturer, or otherwise, does not necessarily constitute or imply its endorsement, recommendation, or favoring by the United States Government or the University of California. The views and opinions of authors expressed herein do not necessarily state or reflect those of the United States Government or the University of California, and shall not be used for advertising or product endorsement purposes.

This work was performed under the auspices of the U. S. Department of Energy by the University of California, Lawrence Livermore National Laboratory under Contract No. W-7405-Eng-48.

This report has been reproduced directly from the best available copy.

Available electronically at http://www.doe.gov/bridge

Available for a processing fee to U.S. Department of Energy

and its contractors in paper from

U.S. Department of Energy

Office of Scientific and Technical Information

P.O. Box 62

Oak Ridge, TN 37831-0062

Telephone: (865) 576-8401

Facsimile: (865) 576-5728

E-mail: reports@adonis.osti.gov

Available for the sale to the public from

U.S. Department of Commerce

National Technical Information Service

5285 Port Royal Road

Springfield, VA 22161

Telephone: (800) 553-6847

Facsimile: (703) 605-6900

E-mail: orders@ntis.fedworld.gov

Online ordering: http://www.ntis.gov/ordering.htm

OR

Lawrence Livermore National Laboratory

Technical Information Department's Digital Library

http://www.llnl.gov/tid/Library.html 
Intermittent Single Point Machining of Brittle Materials

LLNL Subcontract B503785

Submitted to:

Mark Piscotty

Lawrence Livermore National Laboratory

Mailstop L-537

7000 East Ave.

Livermore, CA 94550-9234

Submitted by:

Eric Marsh

Machine Dynamics Research Lab

Penn State University

326 Reber Building

University Park, PA 16802

December 7, 1999 


\section{Summary}

A series of tests were undertaken to explore diamond tool wear in the intermittent cutting of brittle materials, specifically silicon. The tests were carried out on a plain way No. 3 Moore machine base equipped as a flycutter with a motorized Professional Instruments $4 \mathrm{R}$ air bearing spindle. The diamond tools were made by Edge Technologies with known crystal orientation and composition and sharpened with either an abrasive or chemical process, depending on the individual test.

The flycutting machine configuration allowed precise control over the angle at which the tool engages the anisotropic silicon workpiece. In contrast, the crystallographic orientation of the silicon workpiece changes continuously during on-axis turning. As a result, it is possible to flycut a workpiece in cutting directions that are known to be easy or hard. All cuts were run in the 100 plane of the silicon, with a slight angle deliberately introduced to ensure that the 100 plane is engaged in "up-cutting" which lengthens the tool life.

A Kistler 9256 dynamometer was used to measure the cutting forces in order to gain insight into the material removal process and tool wear during testing. The dynamometer provides high bandwidth force measurement with milli-Newton resolution and good thermal stability. After many successive passes over the workpiece, it was observed that the cutting forces grow at a rate that is roughly proportional to the degradation of the workpiece surface finish. The exact relationship between cutting force growth and surface finish degradation was not quantified because of the problems associated with measuring surface finish in situ. However, a series of witness marks were made during testing in an aluminum sample that clearly show the development of wear flats on the tool nose profile as the forces grow and the surface finish worsens.

The test resuits show that workpieces requiring on the order of two miles of track length can be made with low tool wear and excellent surface finish. With longer track lengths, the tool forces (and presumably tool wear) begin a roughly linear increase as surface finish steadily worsens. No catastrophic tool failures were observed, only slow changes as the track length increases.

Interestingly, the specific cutting energy did not remain constant with depth of cut, suggesting that there are significant friction forces in the cutting of silicon. This finding supports published results emphasizing the importance of a large clearance angle on the tool and hints that fairly aggressive cuts may be the most efficient way to remove material. That is, tool life may turn out to scale with track length, not volume indicating that machining parameters for silicon should be chosen to minimize track length by taking heavier cuts. 


\section{Experimental Results}

Each silicon sample was fixtured using gage blocks to a carefully controlled angle on the dynamometer (the crystal orientation of the samples were provided by LLNL). Figure One shows the workpiece fixturing technique.

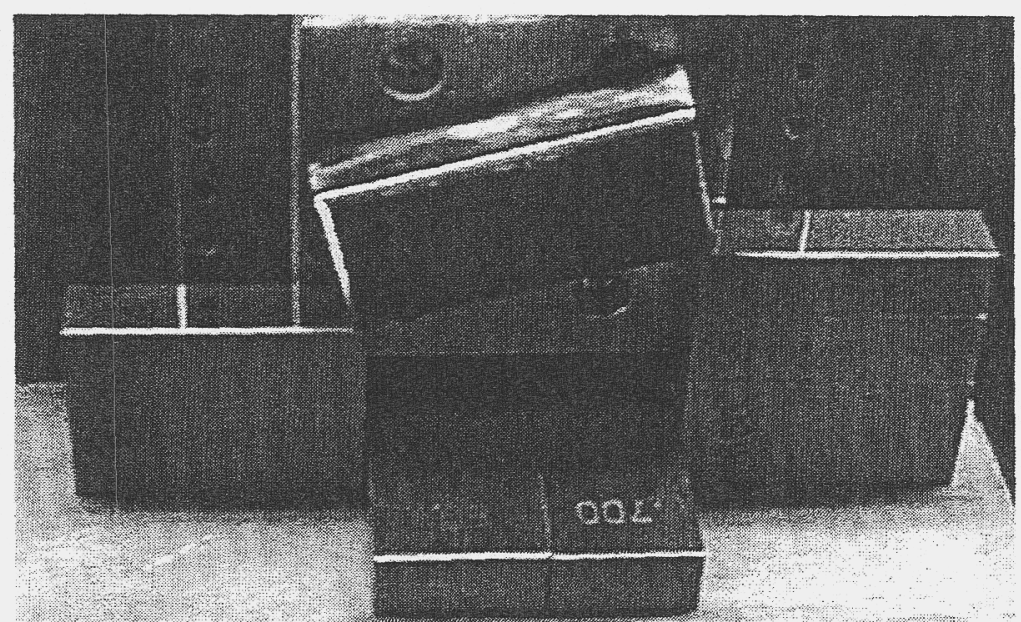

Figure One: Gage block setup to set workpiece angle on dynamometer.

The flycutting machine tool is shown in Figure Two. The machine base is a Moore plain way No. 3 with $\mathrm{DC}$ gearmotors providing $\mathrm{XZ}$ travel. The air bearing spindle is a Professional Instruments $4 \mathrm{R}$ with integral AC motor. A HP 35670A dynamic signal analyzer is used to capture the cutting forces measured by the Kistler MiniDyn 3-Component Dynamometer - Type 9256. A sampling rate of $800 \mathrm{~Hz}$ was typically used to take full advantage of the high bandwidth capabilities of the Kistler while allowing sufficient sample time to capture the entire pass of the diamond tool over the entire workpiece (many minutes long for most feed rates). Some tests were sampled at higher rates and then digitally filtered afterwards to match the bandwidth of the dynamometer. In both cases, proper use of analog anti-alias filtering was observed.

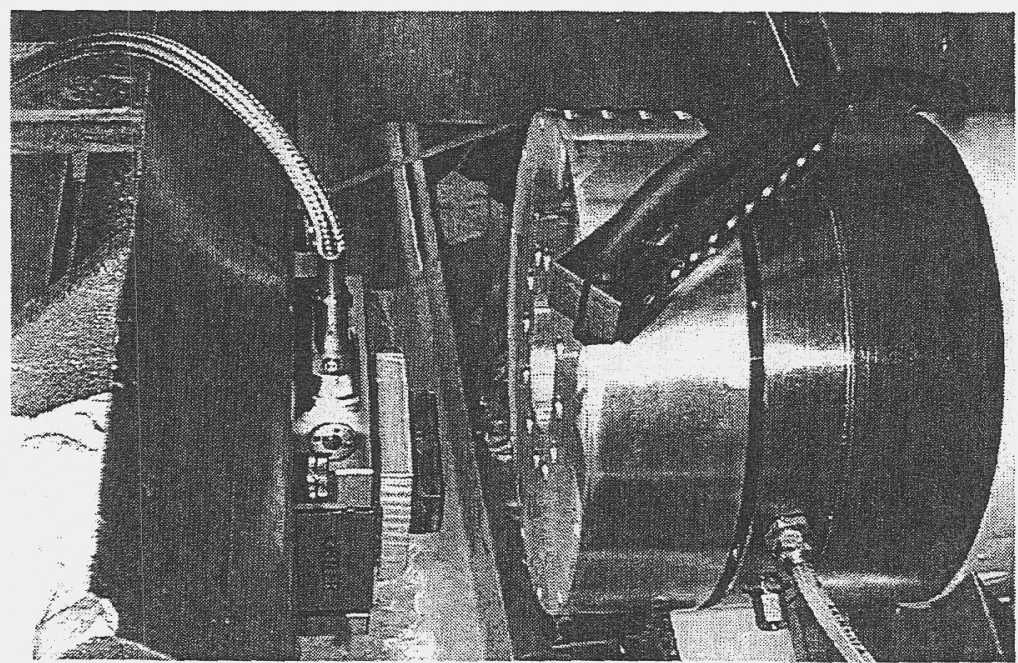

Figure Two: Close up view of air bearing spindle with flycutter head, dynamometer, and silicon workpiece. A hose for coolant is shown above the workpiece/tool contact point. 
Five tools were run until the surface finishes were of visibly poor quality (as characterized by a significant diffraction grating appearance in the surface). The test parameters are outlined in Table One.

\begin{tabular}{|cccccccccc|}
\hline Test DOC & $\begin{array}{c}\text { Rad } \\
\mu \text {-in }\end{array}$ & $\begin{array}{c}\text { Feed } \\
\text { in }\end{array}$ & $\begin{array}{c}\text { Spindle } \\
\text { RPM }\end{array}$ & $\begin{array}{c}\text { Speed } \\
\text { ft/min }\end{array}$ & $\begin{array}{c}\text { Rake } \\
\text { degrees }\end{array}$ & $\begin{array}{c}\text { Sample Chip thick Track/pass } \\
\mu \text {-in }\end{array}$ & miles \\
\hline \hline 0 & 200 & 0.192 & 1000 & 240 & 377 & -30 & $2 / 3$ & 46 & 0.02 \\
1 & 200 & 0.192 & 120 & 477 & 749 & -30 & $2 / 4$ & 5 & 0.17 \\
2 & 200 & 0.200 & 1000 & 477 & 749 & 0 & $1 / 4$ & 45 & 0.02 \\
3 & 200 & 0.060 & 250 & 477 & 749 & 0 & $1 / 3$ & 20 & 0.08 \\
5 & 200 & 0.063 & 250 & 477 & 749 & -30 & $1 / 3$ & 20 & 0.08 \\
\hline
\end{tabular}

Table One: Silicon cutting test parameters

Each tool was tested until the forces became high and the surface finish was visibly poor. Additional pre-tests were performed to verify that good surfaces could be made with fresh diamond tools. Figure Three shows a typical good surface made with a new $(0.25$ mile track length) tool.



Figure Three: Typical silicon surface.

The intermittent contact of flycutting provides a convenient reference for removing any low frequency artifacts that occur as a result of thermal gradients due to changing coolant flow (the location at which the coolant impinges upon the dynamometer changes during the test). A typical force trace with many revolutions of cutting is shown in Figures Four and Five. 


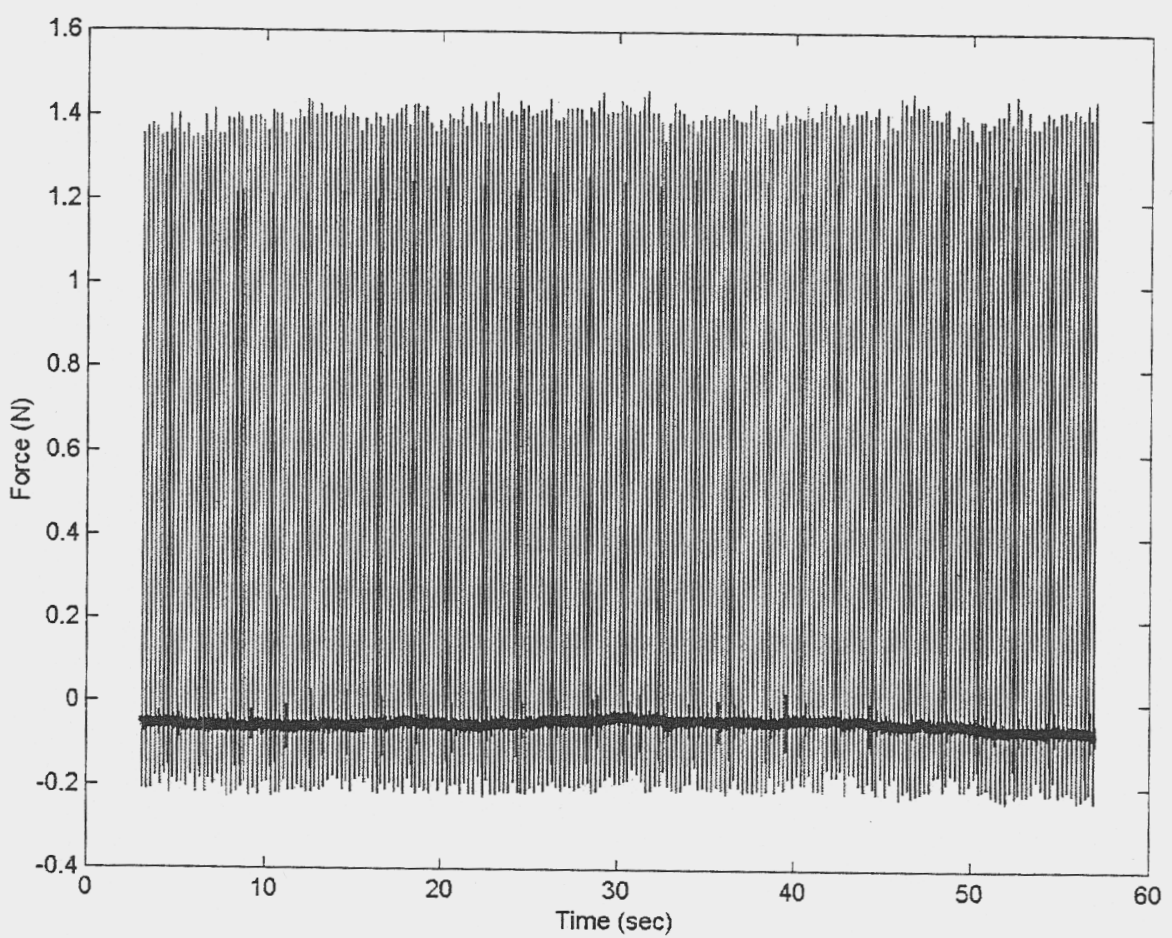

Figure Four: Long cutting force time capture with several hundred passes over the workpiece.

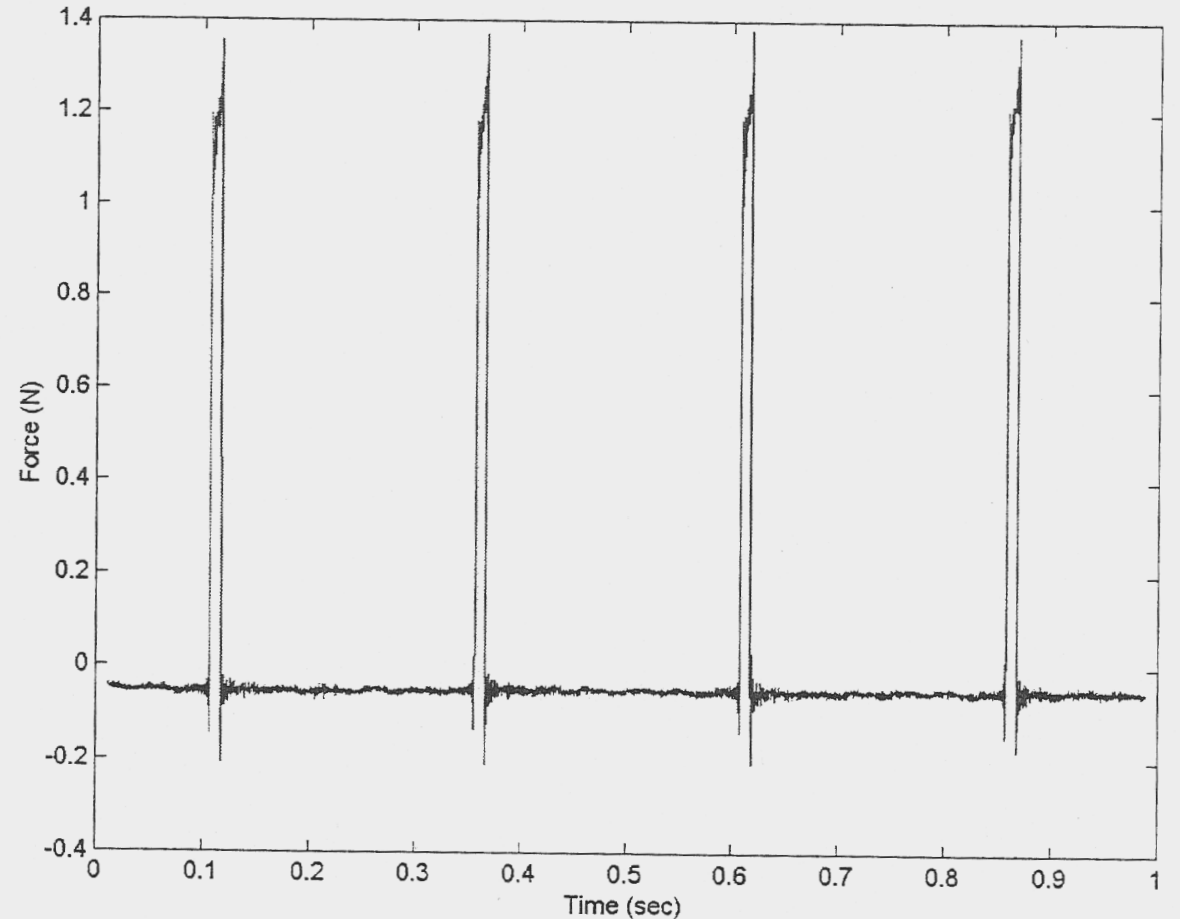

Figure Five: Four consecutive flycutting passes over the silicon workpiece.

Close up inspection of a typical cutting force trace reveals the fine detail as the tool cuts the 0.75 inch length workpiece, as shown in Figure Six. 




Figure Six: Close up of cutting and tangential forces from one cut over the workpiece.

Using data from pre-tests run at varying depths of cut, it was observed that the specific cutting energy does not remain constant, as shown in Figures Seven and Eight. However, the cutting forces do remain constant when normalized by the effective chip thickness given by Equation 1 .

Normalized Specific Cutting Energy

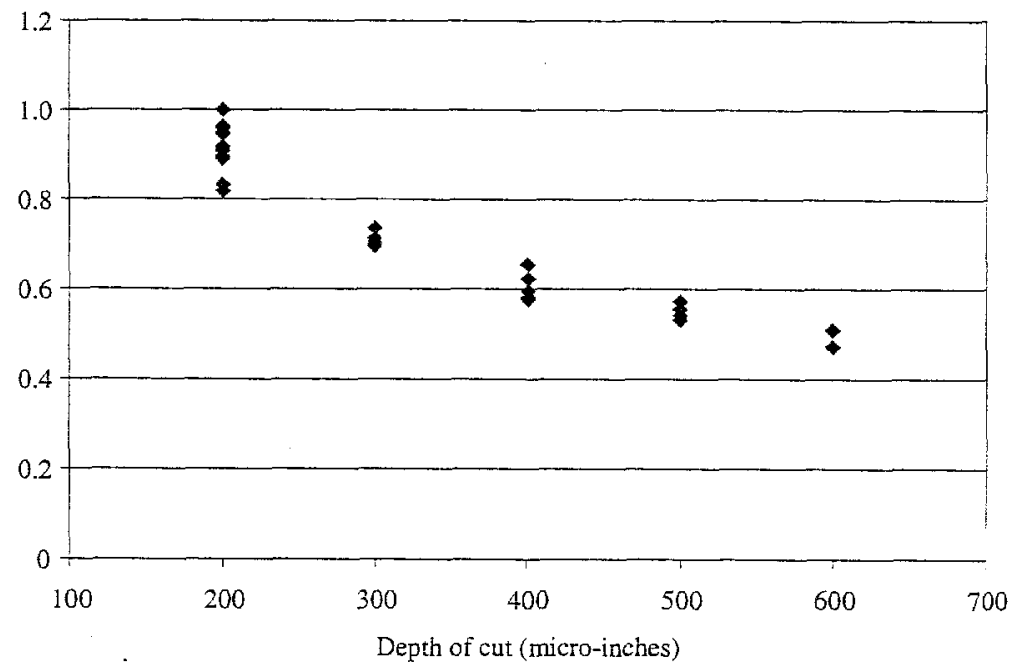

Figure Seven: Normalized specific cutting energy. 


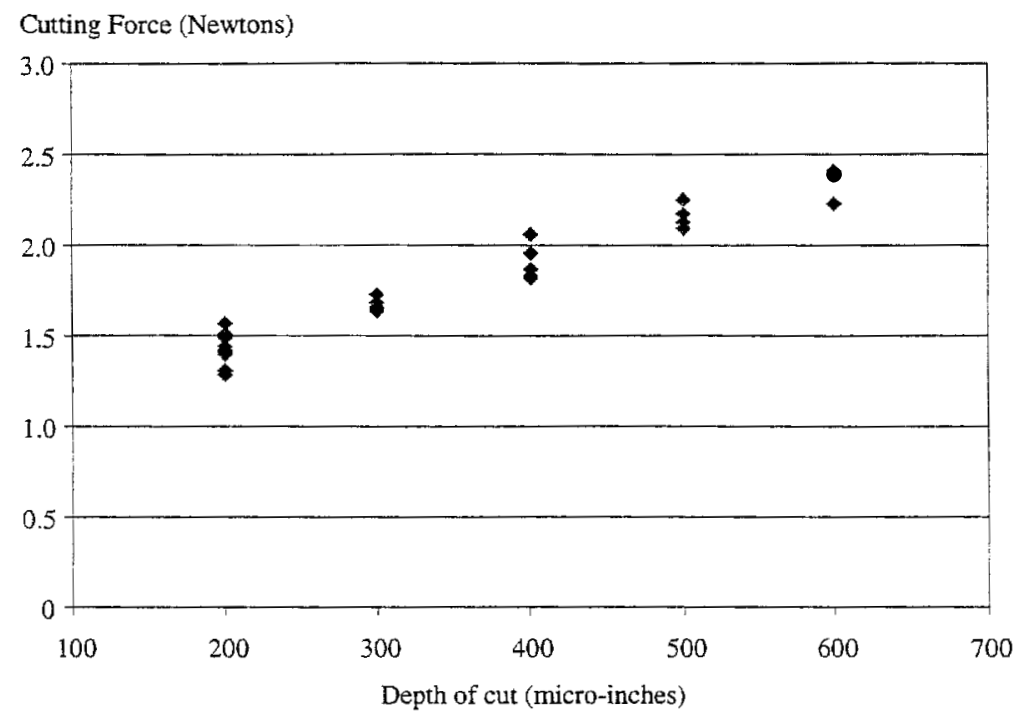

Figure Eight: Cutting force as a function of depth of cut.

where:

$$
t_{c}=f \sqrt{\frac{2 h}{R}}
$$

$t_{c}$ is the effective chip thickness

$f$ is the feed per revolution of the cutting tool

$h$ is the depth of cut

$R$ is the tool radius. 